\title{
Enunciar la frontera sur de México desde la narrativa: algunos cuentos guatemaltecos
}

\section{Portraying the southern border of Mexico within the narrative: Six Guatemalan short stories}

\author{
Marco Antonio Chavarín González* \\ doi.org/10.29043/liminar.v20i2.909
}

Resumen: A partir de una selección de seis textos de tres antologías de cuentos guatemaltecos se hace un análisis que dé cuenta de algunos de los rasgos representativos de la poética de distintos escritores del siglo XX y la primera década del siglo XXI en relación con las preocupaciones que muestran de acuerdo con el momento de la enunciación. En este sentido, se busca, además, poner en diálogo la visión diacrónica de la primera antología, con el regionalismo de la segunda y el reconocimiento de los novísimos escritores de la tercera.

Palabras clave: cuento guatemalteco, narrativa hispanoamericana, literatura y sociedad.

Abstract: Based on an analysis of six texts from three anthologies of Guatemalan short stories, I endeavor to understand some of the representative features of the poetics of 20th and 21st century writers in relation to the concerns they reveal, in keeping with the times in which they were written. In this sense, I also try to encourage dialogue between the diachronic vision of the first anthology with the regionalism of the second, while recognizing the newest writers of the third anthology.

Key words: Guatemalan short stories, Hispanic American narrative, literature and society. 


\section{Introducción}

$\mathrm{E}^{\prime}$ 1 corpus específico seleccionado para este artículo es de seis cuentos que se consideran representativos de la narrativa guatemalteca: "Nuestra señora de los locos", de Rafael Arévalo Martínez e "Imitando se entiende la gente", de Rafael Romero; "El vuelo de la Jacinta", de Raúl Carrillo, y "Morgan”, de Francisco Alejando Méndez; y "Mañana nunca lo hablamos", de Eduardo Halfon, y "El iluminado" de Leonor Paz y Paz. ${ }^{1}$ Cada uno de estos cuentos, como se verá a continuación, corresponde a una de tres antologías y su revisión tiene la intención de dar cuenta de las relaciones existentes entre los autores canónicos y los que empiezan a serlo, según el criterio de selección de cada una. "Nuestra señora de los locos" pertenece a Narrativa guatemalteca. Antología (Alfaguara, 2011; textos de autores guatemaltecos canónicos del siglo XX y la primera década del siglo XXI); "El vuelo de la Jacinta" y "El iluminado" a Fuera del círculo. Antología guatemalteca II (Alfaguara, 2013; autores guatemaltecos de distintas regiones del siglo XX y XXI); e, "Imitando se entiende la gente" "Morgan” y "Mañana nunca lo hablamos" a Ni hermosa ni maldita. Narrativa guatemalteca actual (Alfagura, 2012; autores guatemaltecos novísimos).

Es decir, el corpus es una selección de una selección de especialistas en literatura guatemalteca que se complementan entre sí; por ejemplo, en la primera antología, según el coordinador, la “intención nunca fue agotar las posibilidades del espejo, sino encontrar lugares intensos, puntos de luz que invitaran a la lectura, que sedujeran, que enamoraran" (Villalobos, 2011, pp. 7); en la segunda, "los cuentos escogidos [...] tienen la intención de dar representación a los territorios y regiones que componen Guatemala" (Albizúrez Palma, 2013b, pp. 9-10), entre ellas, Totonicapán, Jutiapa, Petén, San Marcos, Sacatepéquez, Jalapa, Chimaltenango, Baja Verapaz, Zacapa, Alta Verapaz y Santa Rosa; y en la tercera, se incluyen autores en formación que "nos alejan de aquella Guatemala de pueblos y aparecidos y nos llevan de la mano por espacios donde concurren dinámicas más turbulentas, soledades más extrañas, conflictos más penumbrosos" (Villalobos y Méndez Salinas, 2012, p. 9).

Con el análisis de los seis cuentos referidos, se busca mostrar algunas de las principales preocupaciones de los escritores guatemaltecos en sus distintos momentos de la enunciación —realidad histórica desde la que el autor empírico escribe-, preocupación que concuerda con la visión del mundo que ciertos grupos tuvieron en cada uno de esos distintos momentos. En este sentido, los textos narrativos analizados se consideran como un discurso que se construye en una realidad específica a partir de esa misma realidad y, de acuerdo, con la visión del mundo con la que el autor empírico coincide. Es decir, se considera que cada texto analizado, además del nivel estético —o estructural—y del estilístico, en los que el escritor tiende a poner el énfasis, importa el nivel ético, el del contenido, que de manera más o menos directa alude a elementos de la realidad del autor empírico.

Desde esta perspectiva no es tan importante identificar cada uno de los hechos reales a los que se alude en los cuentos que se revisan sino solo las significaciones que de esos posibles hechos reales parece hacer el escritor. En este sentido, algunas de las temáticas que alcanzan a percibirse en los distintos textos son: la migración, la marginalización o el fracaso económico y social del individuo, los cacicazgos, la violencia,

\footnotetext{
${ }^{1}$ Este artículo es resultado de una revisión hecha para un apartado del Objetivo " $n$ " del Proyecto Región Transfronteriza México Guatemala - Análisis del discurso del gobierno nacional de Guatemala sobre la frontera con México-.
} 
la relación entre el campo y la ciudad, el rompimiento de las tradiciones, las guerrillas, la esclavitud, el incesto, la añoranza del pasado, la concientización social, la manera en la que la tecnología y las visiones del mundo de la posmodernidad afectan al sujeto y la homosexualidad, entre otras. Como quizá se observe, ninguno de estos temas sobresale por su originalidad, son temas que aparecen en la literatura de todos los países; sin embargo, lo que de importante tienen para este artículo está en la especificidad que cada uno de los seis escritores, desde los distintos niveles del texto, fue capaz de otorgarle a partir de su relación con Guatemala en un momento histórico específico.

\section{Rafael Arévalo Martínez y Rafael Romero: dos generaciones, una idea sobre la psicozoología}

Uno de los textos más importantes de la primera antología es "Nuestra señora de los locos", de Arévalo Martínez (1884-1975). . La historia transcurre en Santa Rosa, configurado como un pueblito de Guatemala, y se construye a partir de la visión del narrador-personaje, Friend, y de su capacidad, junto con la de su hermana, una jovencita deforme, de ver a las personas como animales. La narración se centra, básicamente, en el tiempo en que la protectora de ambos y de un conjunto de personajes marginales, la señorita Ema Eguilaz, - "una bellísima paloma. Llena, llena, llena, toda parte de su cuerpo era mórbida. Baja. Blanca, blanca, blanca, toda ella estaba vestida de plumas blancas. Y había nacido para el amor conyugal. Todo en ella aromaba de castidad sensual. Era arrulladora y arrullante. Tan casta, tan casta; y tan amorosa, tan amorosa" (Arévalo Martínez, 2011, p. 40) - se casa con el licenciado Reinaldo - "la eterna serpiente que había seducido a la mujer; la eterna serpiente; de fascinadora frase bíblica, que sabía hacerse oír de la mujer" (2011, p. 55) - . Como se observa, es llamativo que Eguilaz sea vista como una paloma y Reinaldo como una boa constrictora que es capaz de hipnotizar a sus víctimas, a pesar de que el mismo apellido de Ema haga pensar más bien en un águila, un ave de rapiña.

Según lo que deja ver el narrador, quien aparenta tener la visión de un joven inocente y de intelecto limitado - aunque es mucho más astuto de lo que deja ver-, Ema únicamente se casó para tener un hijo, pues no solo huye de Reinaldo al siguiente día de la noche de bodas sino que los esposos no vuelven a verse y "la señorita Eguilaz vive [veinte años, momento desde donde el narrador enuncia] la vida más pura que conozco, sola con su hijo Salvador, en su posesión de la aldea [...] Así fue como la señorita Eguilaz fue madre. Yo comprendo algo. Yo vagamente comprendo algo. Yo sé que no pudo ser de otra manera" (Arévalo Martínez, 2011, p. 57). No es la intención del autor aclarar directamente todas las dudas, por ello nunca se explica claramente en el cuento si Eguilaz obtuvo con su matrimonio alguna ventaja económica o de otro tipo. Pareciera, de pronto, que las acciones de los personajes responden a razones muy particulares y que la imposibilidad de entenderlas a cabalidad es lo que el autor busca. Lo que sí está claro es que después de la noche de bodas y de quedar embarazada, Ema vuelve a ser la señora de los locos.

\footnotetext{
${ }^{2}$ Eduardo Villalobos señala que Arévalo Martínez nació en Guatemala en 1884 y murió en 1975, que fue director de la Biblioteca Nacional, poeta - Los atormentados (1914) -, narrador -El hombre que parecía un caballo (1915) y Hondura (1959) - y ensayista — iEcce Pericles! (1945) —, que perteneció a la Generación de 1910 -Juan Carlos Escobedo Mendoza le llama, también, la Generación del Cometa - y que colaboró en varios periódicos del país como El Imparcial, Diario de Guatemala y La República (Villalobos, 2011, p. 174).
} 
Uno de los elementos que más llama la atención de este cuento, como quizá se haya percibido en la descripciones de Ema y Reinaldo, es la capacidad que el narrador-personaje tiene para asimilar las crisis a partir de su peculiar forma de ver el mundo, una visión psicozoológica, que, en palabras de Francisca Noguerol Jiménez, se refiere al tratamiento de "la psicología de personajes excepcionales a partir de su comparación con diferentes animales" (Noguerol Jiménez, 1998, p. 203), como en "El hombre que parecía un caballo", el cuento más conocido de Arévalo Martínez. En este último texto, como refiere María A. Salgado en cuanto a uno de sus aspectos, "se trata de un caso del desdoblamiento de la personalidad del narrador, identificado con el autor; esta interpretación apunta hacia los dos niveles del ser humano: su animalidad y su espiritualidad" (Salgado, 1977, p. 778). En el caso de "Nuestra señora de los locos", sin embargo, la psicozoología se ficcionaliza, y el narrador-personaje lo asume como contagio de locura o como participación en la clarividencia de su hermana. Es decir, la psicozoología se entiende en la narración como un elemento que diferencia a unos personajes de los que se pudieran suponer normales y los hace parte de un grupo marginal: "Entonces en el pueblo nos llamaron los hermanos locos" (Arévalo Martínez, 2011, p. 38); sin embargo, esa misma marginalidad parece dotar a los personajes de una perspectiva privilegiada del mundo, $y$, en lo particular y al menos en el narrador, de una conciencia por encima del resto.

Como señala Amparo Muñoz Reoyo, la propuesta estética para la narrativa guatemalteca que hace Arévalo Martínez al poner énfasis en el instinto, inconsciente, subconsciente o ello, como quiera llamársele, en "El nombre que parecía un caballo":

[...] adquiere significación en la medida que ilumina el camino hacia la vanguardia. La trama en sí carece de importancia y la acción narrativa es mínima. Lo sorprendente, en raro alarde de anticonvencionalismo, es la inclusión dentro del espacio de la ficción de toda una serie de relaciones extratextuales que permanecen tematizadas en el ámbito del relato (Muñoz Reoyo, 1997, p. 328).

Sin embargo, más que estos aspectos estéticos como la relación con el modernismo o la vanguardia, la prefiguración de una especie de surrealismo o realismo mágico o la apertura hacia lo fantástico, que Muñoz Reoyo menciona más adelante, lo que importa para el presente artículo es la trascendencia socialmente significativa de los distintos elementos al interior del texto.

En este sentido, un elemento que ha sido señalado por algunos críticos en el cuento de "El hombre que parecía un caballo" es la idea de "una relación homosexual entre el narrador y el señor de Aretal" (Salgado, 1977, p. 779) y, según Raymond Albert Moody, "la ostentación y la homosexualidad son las más obvias características de su personalidad y ellas apuntan hacia un intenso egocentrismo, el cual imposibilita un comportamiento y relaciones más normales" (Moody, 1967, p. 359). Parafraseando, de acuerdo con Moody, el tipo de relaciones que el narrador establece y la visión psicozoológica son consecuencia de la tendencia del narrador a la ostentación, su marcado egocentrismo y una manera de lidiar con la homosexualidad. Así, desde esta perspectiva, una lectura de los niveles ético y estético de "El hombre que parecía un caballo" implicaría considerar que, en vez de negar la homosexualidad, Arévalo Martínez la oculta tras la configuración de los personajes y el planteamiento de sus relaciones.

No hay que olvidar, como explica Carmen Lucía Alvarado, que: 
[...] de los rasgos estéticos que puedan llegar a entrelazar a una generación, hay que tomar en cuenta también el contexto en que se formaron, y ésta es una de las características más claras de esta generación, formada bajo la dictadura de Manuel Estrada Cabrera, una represión que pudieron combatir a través de su arte (Alvarado, 2013).

Respecto de Estrada Cabrera, quien gobernó Guatemala de 1898 a 1920, se refiere que, durante su mandato de más de veinte años, "no tolera ningún tipo de oposición y comienzan a darse una serie de crímenes políticos, torturas en la Penitenciaría central y Fusilamientos de numerosas personas de la oposición" (EcuRed, 2019). En este sentido es que importa comentar lo que parece ser un intento por ocultar el contenido desde el nivel estructural del texto, intento que, por sí mismo, incita a considerarlo un referente polémico, sea ideológico o no. La homosexualidad, desde esta perspectiva y sobre todo en un régimen como el señalado, resulta subversiva, pues "la diversidad sexual es un asunto de trascendencia social, necesario en el desafío de culturas hegemónicas y en la discusión del heterosexismo y, por ende, de transformación y subversión sociales" (Ceballos-Fernández, 2014, p. 655).

De forma similar a "El hombre que parecía un caballo", en "Nuestra señora de los locos", la visión psicozoológica implicaría un intento por esconder-aludir a problemas más profundos, así como una forma de lidiar con la marginalidad. Por ello, Reinaldo, el abogado seductor y egocéntrico, triunfador en lo profesional y en lo económico, un miembro destacado y aceptado por su sociedad, se ve como una boa "hermosamente fea", el sacerdote que impidió su entrada a la iglesia por algún tiempo, como un ternero, algunos ciudadanos del pueblo, una potencial amenaza, como tigres, otros, poca amenaza, como garduñas y su protectora, Ema, como una paloma blanca. Según se observa, la propia comparación con el animal funciona como una especie de juicio sobre el personaje.

En este sentido, es todavía más significativo que en "Imitando se entiende la gente", de Rafael Romero, ${ }^{3}$ se acuda al mismo motivo, el de la ficcionalización de la psicozoología, la comparación entre personas y animales. Y me interesa hacer énfasis en la continuación de la temática, porque Romero nació tres años después de la muerte de Arévalo Martínez, es decir, mientras el segundo pertenece a la llamada "Generación de 1910 o del Cometa", acotada, como se mencionó arriba, por el gobierno de Estrada Cabrera, el primero pertenece a la de los nuevos escritores del siglo XXI, los nacidos en las últimas cuatro décadas del siglo XX, la denominada mundialmente como Generación X. El cuento de Romero trata sobre Bernalito Díaz, a quien el narrador define como: "etólogo empirista; es decir, un estudioso amateur del comportamiento animal en relación comparativa con la conducta humana” (Romero, 2012, p. 75). Este personaje es presentado como una especie de predicador al que se le cede la voz para que se explaye. Sus enseñanzas, vale comentar, se basaban en la hipótesis de que los humanos habían llegado a ser quienes eran imitando a los animales.

Un elemento que sobresale en la configuración del cuento es que la voz del narrador se limita a ser casi un acotador de las acciones del personaje de Bernalito, pues trata de intervenir lo menos posible. Esta particularidad del nivel estético se vuelve parte del nivel ético, cuando, casi al finalizar el texto, el

\footnotetext{
${ }^{3}$ Según Eduardo Villalobos y Luis Méndez Salinas, Rafael Romero nació en Jocotenango, Sacatepéquez, Guatemala, en 1978. Es narrador -El elegido (2011) y Génesis y encierro (2011) - , poeta —Distención del ansia (2011) - y académico. Su tesis de licenciatura fue sobre La Puerta del Cielo, del también escritor guatemalteco Luis de Lión (Villalobos y Méndez Salinas, 2012, p. 186).
} 
narrador se llama a sí mismo "camarada e implícito discípulo suyo" (Romero, 2012, p. 79), de Bernalito; es decir, el tono irónico - y, por tanto, descalificador de los hechos narrados- que se cree percibir a lo largo de todo el texto de parte del narrador proviene, en realidad, de la voz del autor implicado, pues el propio narrador es también objetivo de la ironía, debido, principalmente, a que es un emisor inocente, un personaje que cree en la filosofía expuesta por Bernalito. De alguna manera, esta revelación se vuelve parte de la sorpresa final que concluye con una especie de fiesta furry o yiff, ${ }^{4}$ organizada por el narrador, en la que se convierte el velorio del protagonista: "me atreví a organizar un solemne simulacro de la entrada de los animales al Arca de Noé y lo llevamos a cabo con los asistentes. Además, instigamos a que cada animal hiciera sus sonidos respectivos, para darle más realce al evento: onomatopéyico concierto que alcanzó su clímax cuando escenas de galanteo y apareo se sucedieron sin que nadie lo impidiera. Una cosa lleva a la otra. El poder de los sonidos, el llamado de la selva” (Romero, 2012, p. 80).

Lo interesante de la supuesta inocencia del narrador es que permite, con aparente recelo moral —que sabemos que no existe cuando se revela como discípulo de Bernalito, pero que tiene la función de liberar al lector o lectora de cualquier prejuicio y, como consecuencia, desarmarlo-, transmitir y narrar con un buen grado de naturalidad las ideas y las acciones de la historia, a través de afirmaciones — a veces en discurso directo y otras en indirecto- como:

los chiquillos lloran exactamente como los gatos en plena cópula nocturna [lo que lo lleva a concluir que...] El lenguaje sexual de los felinos, por consecuencia, dio origen a nuestro lenguaje [o...] Un caballo que en su establo se mecía de un lado para otro desaguando orín y estiércol a la vez, fue la inspiración para que Pollock inventara el famoso dripping y su pintura se asociara al pragmatismo [o, incluso, que...] Un día, entre sus muchas disertaciones al aire libre, se atrevió a negar que la zoofilia fuera una desviación sexual o algo perverso. Adujo, más bien, que se trataba de un retorno a los estados primigenios del ser humano, en donde el salvajismo era una forma aceptada de vida (Romero, 2012, pp. 75-77).

Como se observa, existe una especie de gradación ascendente en cuanto al nivel de las opiniones de Bernalito respecto de lo que se podría considerar como "normal"; pues, tales observaciones se ven matizadas por una especie de humor en el caso de la pintura de Pollock o en ese "se atrevió a negar" con el que el narrador parece descalificar implícitamente - lo que sabemos que no es-, simulando, así, apegarse a esa "normalidad" que tendería a desautorizar, en automático, las ideas de Bernalito. En este mismo sentido, puede considerarse que tras la muerte de Bernalito, los familiares y el narrador -queriendo cumplir con su última voluntad y después de que las autoridades les negaran la posibilidad de enterrarlo en el zoológico - procedieran a pedir que lo dieran de comida a los cocodrilos o a los tigres del zoológico, ofreciendo "pagar con algunas semillas de cacao si es necesario; [pero...] Como era de esperarse, sus súplicas no fueron escuchadas” (Romero, 2012, p. 80). Con esto concluye el cuento, que

\footnotetext{
${ }^{4}$ Según Francisco Javier Gallardo Linares, el término furry, que alude a humanos disfrazados con trajes de animales antropomórficos, refiere "1) Productos artístico con animales o criaturas antropomórficas. 2) Subcultura o comunidades relativas a estos productos artísticos (el fandom). 3) Identificación relativa a esta subcultura [en tanto que el yiff se refiere a...] pornografía relativa al género artístico furry, generalmente dibujos; también puede referirse a juegos de rol sexuales en internet o sencillamente como sinónimo de sexo" (Gallardo Linares, 2013, p. 10).
} 
enfatiza, de alguna manera, la atemporalidad de los preceptos de Bernalito, sobre lo que, por un lado, se ironiza, pero que, también, por el otro, se normaliza como una especie de injusticia.

Puede decirse, entonces, que la diferencia básica entre "Nuestra señora de los locos" e "Imitando se entiende la gente" — a pesar de que su intención sea la misma, ficcionalizar la psicozoología — es que en el primero Arévalo Martínez parece alegorizar comportamientos humanos todavía no aceptados, incidiendo con ello, además, en lo político e intentando, de alguna manera, evitar la censura desde la dictadura; en tanto que Romero parece querer dar cuenta de las implicaciones que todo intento de significación del mundo - más o menos coherente, como cualquier religión - tiene sobre los receptores del mensaje, por más absurdo que parezca. A la vez, Romero advierte, desde los niveles estético y estilístico, de lo engañoso que puede llegar a ser un discurso aparentemente normal, pues un emisor que parece poner ciertos reparos morales o de sentido común a las palabras de otro puede estar haciendo propaganda a favor de ese discurso, en el caso de este cuento, una especie de evangelización después de la muerte del líder, Bernalito. Es decir, ambos textos —el de Arévalo Martínez y el de Romero- revelan, a fin de cuentas, preocupaciones distintas debido a problemas específicos del momento de la enunciación.

\title{
La perspectiva sobre la marginalidad de Raúl Carrillo y Francisco Alejandro Méndez
}

De los cuentos que aparecen en la segunda antología, quizá el más fuerte por la temática tratada, pero también uno de los más ágilmente presentados y que evita caer en el panfleto, es "El vuelo de la Jacinta", de Raúl Carrillo. ${ }^{5}$ En el texto se narran, en un espacio-tiempo donde no deja de llover, los hechos posteriores al suicidio de Jacinta, así como algunos pasajes previos que la llevaron a ello. Jacinta era una adolescente que quedó embarazada tras ser víctima de las constantes violaciones de su padre. El narrador, que permite a Carrillo tratar el tema sin evidenciar el elemento crítico, es un niño, el hermano de Jacinta, quien también fue víctima de la violencia, junto con su madre, del padre, quien, además, era alcohólico. El narrador da cuenta de los abusos desde su perspectiva infantil y con la naturalidad de un sujeto marginal que los vive todos los días: "hace días que solo a mí me pega. A mí o a mi mamá. A ella [Jacinta] últimamente le pegaba poco". Sin embargo y a pesar de ser un niño, la causa de ese cambio en la relación con el padre la entiende a la perfección:

\begin{abstract}
A Jacinta ya no le pegaba tanto desde que ella se mantenía en la casa haciendo todos los quehaceres mientras mi mamá andaba lavando. Él cree que yo no sé las cosas. Ya no le pegaba tanto desde que se la trincó [...] A mí ya me tiene maduro a pencazos. Y a la pobre Jacinta la usaba sin medida como si no hubiera sido su hija. Ella decía que desde que mi papá empezó con esas babosadas, a ella le principiaron los ataques. Puro castigo de Dios. Yo más bien creo que fue un leñazo que mi papá le dio cuando era más chiquita. Me acuerdo que la llevaron al hospital y que mi mamá dijo que se había caído de un guayabo. Quien sabe... (Carrillo, 2013, pp. 38-39).
\end{abstract}

\footnotetext{
${ }^{5}$ De acuerdo con Francisco Albizúrez Palma, Raúl Carrillo es un narrador de tendencia naturalista nacido en Flores, Petén, Guatemala, en 1925. Otros cuentos de él son: "Cuentos de hombres" (1958), "Lo que no tuvo nombre" (1974) y "Yo soy mi padre" (1993) (Albizúrez Palma, 2013c, p. 35).
} 
Además de los elementos ya mencionados y de que la madre encubría al padre, en este fragmento se puede ver la capacidad del narrador para entender su mundo y cuestionarlo; por ejemplo, según el narrador, los ataques que le daban a Jacinta después de las violaciones eran a causa de la violencia de la que fue víctima cuando era más joven y no tenían de fondo una razón religiosa, sino algo totalmente físico. La aparente falta de crítica en los comentarios del narrador resulta sumamente llamativa y es explicable por su edad y en su mundo, y entendible si se toman en cuenta dos apartados: el primero que se refiere a la noche en que Jacinta fue violada por primera vez:

Ella no quería a mi papá. Me decía que una noche de tantas iba a matarlo. Que le iba a meter un cuchillo cuando estuviera dormido. Porque le pegaba mucho a mi mamá. Y también a nosotros. Pero desde el día que él la sopapeó y le tronchó los brazos para que se dejara, la Jacinta ya no decía nada. Yo lo vi todo. El me pateó y me echó a la calle. Pero solo caminé hasta la esquina y me regresé a espiar por las rendijas. Cuando mi hermana pujaba y se retorcía, sentí basca. Pensé ir a buscar auxilio, pero quería mirarlo todo y me quedé. Después la Jacinta lloraba. Y cuando mi papá se durmió, entré a lavarle su ropa porque ella no se podía mover de todo lo que le hizo (Carrillo, 2013, pp. 39-40).

En este pasaje se nota la destrucción de la capacidad crítica y de la voluntad de Jacinta a través de un sometimiento total que se hace patente aquí, principalmente, a través de las constantes violaciones; sometimiento que trasciende de Jacinta a la madre y al niño. No existe, como puede verse y es de esperar, un vínculo emocional entre Jacinta y el niño con el padre abusador, pero además tampoco existe un esquema de valores que les cause algún conflicto al hablar de asesinar al padre. Sobresalen también las reacciones del narrador que dan cuenta de cierto sentido ético instintivo y que contrastan con las decisiones que tomó: en vez de ir a pedir ayuda se quedó viendo "por las rendijas" cómo su padre violaba a su hermana, lo que implica no solo la desobediencia y reto al padre sino también cierto sentido de curiosidad sexual —algo presentía - que contrastan con ese "sentí basca" y con que ayude a la hermana lavándole la ropa. De alguna manera, sin embargo, las acciones del padre parecen estar formando al niño.

El segundo pasaje que simula esa aparente falta de crítica en la que se establece la visión del mundo del narrador es el que revela los juegos que el narrador mantenía con Gloria y María, las hijas del sastre del pueblo y amigas de él:

Me contaron que su papá les había dicho que [Jacinta] se iba a condenar para siempre por haberse tomado las pastillas. Y que se murió en pecado mortal. Quien sabe [...] Querían que me fuera con ellas al cementerio pues su papá les dio para la camioneta. Nos quedamos hablando. Ellas querían que jugáramos de casados, siempre lo hago con las dos, pero hoy por más que quise no pude. No sentía ganas y estaba pensando en otra cosa. Después nos fuimos al rezo. Atravesamos el patio bajo el agua cobijándonos bajo los cafetales que estaban destilando. Todo está lleno de charcos y de corrientes. No se mira cielo sino pura llovizna. Desde lejos se oye el ronroneo de todas las viejas rezando las avemarías para que Dios perdone a la Jacinta... (Carrillo, 2013, p. 41).

La naturalidad con la que habla de los juegos que llevaba a cabo con las niñas puede implicar, por supuesto, poca malicia, pero también habla de que no es capaz de emitir todavía juicios sobre sus acciones o de que en su mundo los juegos sexuales son comunes a su edad. Es decir, la falta de crítica que salva al texto de 
caer en el panfleto se debe a la perspectiva infantil del narrador en relación con la doble marginalidad de la que es ejemplo - pobre y niño-. Sin embargo, el sentido ético instintivo aparece en el hecho de que por más que quiso jugar a los casados no pudo porque "estaba pensando en otra cosa".

Esta forma de asimilar el mundo, casi por inercia, por instinto, se nota también en que el narrador no asiste al entierro de su hermana y prefiere esconderse entre los cafetales. A pesar de esto, no hay que olvidar que cuando despierta el narrador, la madrugada del suicidio de su hermana, se entera de que está muerta y se duerme rezando para que vuelva. Es decir, no solo está familiarizado con la muerte — sabía que su hermana estaba muerta - sino también creía en la posibilidad de un milagro. Lo que contrasta, de nuevo, con su comentario: "Yo creo que mi hermana iba a tener un hijo y por eso se tomó todas las pastillas" (Carrillo, 2013, p. 42). En otras palabras, el niño parece moverse entre el deber ser y el ser, en un mundo donde las ideas sirven solo de consuelo para asimilar la realidad. En este sentido, hacia el final, es muy significativo el contrapunto entre los pensamientos del niño y las plegarias de los asistentes a la novena por Jacinta:

Afuera la lluvia está arreciando y le hace como segunda a las plegarias. / -Madre del buen consejo... / -RUEGA POR NOSOTROS... / No me puedo dormir de tanto ver las sombras que se mueven con el resplandor de las candelas y oyendo el chisbiriseo de todo lo que rezan en el otro cuarto. Mi papá lleva la voz en las letanías. Se le conoce que está medio borracho por el hablado ronco y salivoso. / - Refugio de los pecadores... / -RUEGA POR NOSOTROS... / Comenzaron a rezar después que se comieron los tamales y se acabaron el aguardiente [...] -Espejo de justicia... / - RUEGA POR NOSOTROS [...] De veras que está lloviendo sobre mojado. / -Estrella de la mañana... / -RUEGA POR NOSOTROS... / Es el temporal... (Carrillo, 2013, pp. 42-43).

Como se observa, una realidad casi poética — la manera de referirse al agua — contrasta con una realidad burda - la de la borrachera del padre, la de los tamales y el aguardiente - y contrapuntean con la letanía. Esto parece una manera de darle sentido a la falta de crítica del hijo y a la inmoralidad del padre. Es decir, la visión acrítica del niño se debe a que todavía está en formación y a que Carrillo parece no creer necesario enfatizar este aspecto del texto, pues al leerlo, desde los mismos comentarios del niño-narrador - probablemente la voz del autor implicado-, puede tomarse una decisión sobre lo bueno y lo malo, según los parámetros éticos sugeridos por el cuento como una totalidad. Si bien el narrador no emite un juicio explícito, da todos los elementos para que las acciones que se llevan a cabo se puedan enjuiciar. En otras palabras: el cuento no es una apología del incesto y la violación, sino todo lo contrario.

Además, como se mencionó al inicio de este artículo, durante todo el cuento no deja de llover - llover "sobre mojado", dice el narrador-, particularidad que no solo enfatiza la acumulación de pesares que se pueden sumar en personas de determinadas clases sociales, sino también parece simbolizar una especie de diluvio que busca borrar toda huella del mal sobre la tierra. Hecho que no se alcanza si se atiene al pesimismo presente en el texto. Hay, sin embargo, un indicio de optimismo en la conciencia del niño, una conciencia que parece querer despertar, y que es capaz, aunque todavía sin posibilidad de juicio, de describir lo que sucede y de obrar, aunque limitadamente y casi por instinto, de la forma correcta: sabe de 
las violaciones de su hermana por su padre, sabe del alcoholismo del padre, ${ }^{6}$ sabe que su padre golpeaba a su madre y a su hermana e, incluso, intuye la causa del suicidio de su hermana. Esta aparente conciencia integra, de manera adecuada y respetando la verosimilitud, los niveles estético y ético del relato, pues es a partir de la inocencia de un niño pobre y marginal —una excelente máscara - que el autor implicado da cuenta de su visión del mundo.

En este sentido, respecto de la intención de plasmar un mundo marginal desde un narrador aparentemente acrítico como en el cuento de Carrillo, vale la pena revisar "Morgan", de Francisco Alejandro Méndez (2012), ${ }^{7}$ texto donde se da cuenta del regodeo casi placentero que, si se olvida la visión trágica que existe en "El vuelo de la Jacinta", se puede tener en la misma marginalidad. En el cuento de Méndez se narra la historia del encuentro de dos seres marginales: por un lado, un columnista alcohólico y drogadicto, quien es el narrador capaz de relatar, aparentemente de manera acrítica, la serie de acciones que componen el texto. Iris Chávez Alfaro señala que en este cuento, por "medio de la confesión-relato del protagonista, el lector puede penetrar en su mundo íntimo, el mundo del delirio producido por las drogas y el alcohol" (Chávez Alfaro, 2005, p. 19); es decir, esa aparente falta de juicios que le da una interesante frescura al texto tiene que ver, si se acepta la propuesta de Chávez Alfaro, con el delirio y, además, "como sucede en los cuentos de Poe, los narradores de Crónicas suburbanas [libro de Méndez de donde se extrae 'Morgan'], cuentan sus hechos con frialdad y la narración delata una mente perversa, sin ningún control sobre sus instintos" (Chávez Alfaro, 2005, p. 25). ${ }^{8}$ Por el otro lado, el segundo ser marginal es el gato tuerto, que da nombre al cuento, Morgan. La descripción de este último, atrapado entre la pared de un baño y un barril de agua, puede dar cuenta del regodeo en la decadencia:

Allí estaba: un cuerpo negro, negro, iluminado por blancos difuminados en el largo torso del animal con resplandecientes amarillos, casi naranja, entre las orejas y patas traseras. Era una bola de pelos humedecidos. Su hocico destilaba vaho de vientre de rata preñada. La cola, que por momentos dibujaba la clave de sol, estaba cortada, quizá por la descarga eléctrica de algún cable. Un ojo ciego, que en lugar de pupila tenía aún los restos del colmillo de un perro callejero (Méndez, 2012, p. 94).

La descripción enfatiza los elementos desagradables de Morgan porque, como contraparte del narrador y según señala Chávez Alfaro:

[...] el gato es otra máscara del ser humano. También en este cuento se produce la animalización. Este gato de la misma forma que lo hace su amo temporal (es una proyección de su imagen) toma cerveza

\footnotetext{
${ }^{6} \mathrm{Al}$ respecto, Mario Cordero, en "El vuelo de Raúl Carrillo", señala que, como pedagogo que era, Carrillo buscaba dejar mensajes en los niños y luchar contra el alcoholismo (Cordero, 2009).

${ }^{7}$ Según Eduardo Villalobos y Luis Méndez Salinas (2012), Francisco Alejandro Méndez es un narrador —Graga y otros cuentos (1991), Sobrevivir para contarlo (1999), Ruleta rusa (2001), Reinventario de ficciones. Catálogo marginal de bestias, crímenes y peatones (2006) y Completamente inmaculada (2000) - , periodista y ensayista - Hacia un nuevo canon de la vanguardia en América Central (2006) - . Nació en la Ciudad de Guatemala en 1964. Tiene una maestría y un doctorado en Estudios de la Cultura Centroamericana por la Universidad Nacional de Costa Rica.

${ }^{8}$ Como sucede en "El vuelo de Jacinta", la apariencia de acriticidad del texto proviene de la perspectiva del narrador y no de que no haya una postura sobre los hechos narrados por parte del autor.
} 
hasta emborracharse [...] es apaleado, pateado y arrojado. Su amo pretende pagar para que lo maten. La relación amo y mascota es de violencia, de agresión y de ansiedad (Chávez Alfaro, 2005, p. 25).

Aunque en lo general concuerdo con la lectura de Chávez Alfaro en cuanto a que narrador y gato se complementan, creo que precisamente la despreocupación con la que el texto es narrado, otra forma de lograr la simulación de una aparente falta de crítica otorgada por la perspectiva del narrador, evita esa sensación de ansiedad que se cree detectar en el cuento. Tampoco considero que el "temor predomina en el ambiente", como señala más adelante, pues los lazos de amistad temporal entre el narrador y el gato se establecen sobre la base de la mutua desconfianza y la despreocupación: ambos son seres marginales que no esperan nada de nadie y, por lo mismo, no tienen nada que temer ni que perder. En este sentido, la posibilidad de morir o de ser asesinado por alguien cercano sería lo normal. La especie de fiesta del narrador con cuatro conocidos y Morgan puede ayudar a entender su tipo de vida:

Dos horas más tarde fumábamos todos y Morgan bebía cerveza. Estuvimos metidos otros tres días dentro del cuarto hasta que mis amigos comenzaron a enfermarse. A uno le dio la pálida. Vomitó durante casi un día hasta que una ambulancia se lo llevó. Otro dijo que iría al hospital porque sentía que tenía clavada una espina de pescado en la garganta. El tercero decidió regresar en autobús a casa, pero antes de llegar quedó internado en una clínica, donde le inyectaron suero.

El otro, el piloto, estaba desmayado. Pensé que todo lo que esto significaba era que yo tendría que pagar la cuenta, así que pensé tomarme la última cerveza, sacarle las llaves del auto a mi amigo que estaba tirado en el piso y regresar a mi casa a continuar fumando (Méndez, 2012, pp. 99-100).

Como se observa, con explícita despreocupación, se detalla el tipo de vida que el narrador y quienes lo rodean llevan, lo que delata, de alguna manera, la falta de "control de sus instintos" a la que se refiere Chávez Alfaro. No se ve, sin embargo, ninguna mente perversa. Entiendo por qué la crítica guatemalteca lo señala, pero no hay que olvidar que el narrador, a pesar de que pida a su vendedor de drogas o pusher que mate a Morgan, le da de beber cerveza para quitarle la sed, lo ayuda a salir de entre la pared del baño y el barril, le cauteriza la cola, le intenta sacar el colmillo del ojo y le pone un parche, se lo lleva a la playa y luego lo recoge inconsciente de la calle para introducirlo al cuarto y evitar que el administrador del hotel lo dañe. ¿Cómo podría considerarse perversa a una persona así? Esta narración aparentemente acrítica le otorga al cuento cierta agilidad y permite al autor, sin subordinar lo estético a lo ético, dar una visión de ese submundo urbano de la Guatemala del siglo XXI sin entorpecerla con los juicios que de seguro ha de tener al respecto.

Como se mencionó al inicio de la revisión de este texto, hay en el cuento una especie de regodeo en lo marginal, el mundo de las drogas que permite el acceso a la versión de ese otro representativo de lo marginal. Así, si el cuento de Carrillo y el de Méndez tendrían algo en común, eso sería el uso de narradores capaces de no emitir juicios directos sobre lo ético o no de los actos de los que son testigos. Característica que le otorga a cada texto un gran valor estético a pesar de que, por supuesto, en ambos casos el lector o lectora puede tomar la postura que desee después de considerar todos los elementos que el propio autor implicado a través del narrador o de sus comentarios le ha dado. Es decir, por supuesto que hay una propuesta de lectura dada por el escritor; sin embargo, el arte, en ambos textos, está en evitar que el énfasis en el contenido arruine la estructura. 


\section{Del compromiso ideológico en Eduardo Halfon y Leonor Paz y Paz}

Quizá uno de los cuentos que tendería hacia la literatura de compromiso ideológico —en cuanto a que se decanta por una razón extraliteraria que reivindica una idea- es "Mañana nunca lo hablamos", de Eduardo Halfon (2012). ${ }^{9}$ El narrador es un niño de origen judío, de ascendencia polaca y libanesa, y relata sus últimos días en Guatemala durante los enfrentamientos entre el gobierno y la guerrilla en el año 1981 antes de migrar a Miami. Si bien lo que se cuenta en primer plano desde la perspectiva del niño es su vida familiar, el momento histórico referido es muy claro y afecta el futuro del personaje principal. Se narra, en general, sobre el ataque del gobierno guatemalteco a la guerrilla entre julio de 1981 y julio de 1982 y, en particular, sobre el enfrentamiento llevado a cabo en la colonia Vista Hermosa de la Ciudad de Guatemala el 7 de julio de 1981, donde resultan muertos tres mujeres y siete hombres, entre ellos uno identificado como Roberto Batz Chocoj de 20 años de edad (Equipo Nizkor, 2011).

Según Sergio Guillermo Palencia-Frener: “Una rebeldía recorría las montañas y llanos de Guatemala en 1981 [...] El temor del Estado se había concretado y las comunidades indígenas habían confluido con la lucha armada revolucionaria" (2014, p. 164). En este sentido es que pueden entenderse los comentarios del narrador del cuento de Halfon respecto de la identificación automática que las clases altas guatemaltecas hacían entre indígena y guerrillero. Por ejemplo, cuando por el enfrentamiento entre la guerrilla y el ejército se suspenden las clases y el narrador va con su amigo Óscar a pasar el día, se lee: "Me quedé mirando los rostros de los militares [en el periódico], tan morenos y tan indígenas como el rostro del guerrillero de la guitarra y el televisor. No entendí. ¿Los militares también eran indígenas? ¿No era todo indígena un guerrillero? ¿Quién era, entonces, un guerrillero?" (Halfon, 2012, p. 59). Aunque, como se aprecia, hay un claro clasismo y racismo, que emerge naturalmente del niño en representación de lo que las clases dirigentes y económicamente pudientes de Guatemala pensaban, el trasfondo histórico remite a los inicios de esa integración, entre indígena y guerrillero, integración que, según Palencia-Frener (2014, p. 164), al final no se dio completamente.

Respecto de la manera en que Halfon integra historia y ficción, se pueden contraponer dos pasajes del cuento, uno que refiere la experiencia del niño como miembro de su clase y, en cierto sentido, ajeno a lo que sucede y, otro, que especifica el hecho histórico del enfrentamiento. El primero:

Los primeros disparos habían sonado a las diez de la mañana. Yo no los oí. Pero supe, por la gravedad en los rostros de mis compañeros, en el rostro de Óscar, que algo importante había ocurrido. Casi inmediato oímos otra ráfaga, y luego otra más aguda. Como respondiéndole a la anterior. Era un jueves. Era el verano del 81 [...] Todos juntos cantamos varias canciones en inglés, mientras Miss Jenkins llevaba el ritmo con aplausos, mientras seguían sonando las ametralladoras, y los escopetazos, los balazos esporádicos, y de pronto, tras segundos de silencio, un inmenso estallido que sacudió todo el colegio y nos dejó quietos y mudos del miedo [;...] los profesores y directores del colegio [...] deci-

\footnotetext{
${ }^{9}$ De acuerdo con Eduardo Villalobos y Luis Méndez Salinas, Eduardo Halfon nació en la Ciudad de Guatemala en 1971 y es un narrador que ha publicado Esto no es una pipa, Saturno (2003), De cabo roto (2003), El ángel literario (2004, semifinalistas para el Premio Herralde de Novela), Clases de Hebreo (2008) y Clases de dibujo (2009; XV Premio Literario Café Bretón \& Bodegas Olarra), entre otros (Villalobos y Méndez Salinas, 2012, p. 187).
} 
dieron llevarnos a todos al gimnasio [...] Y allí, con el constante eco de disparos y bombas y sirenas siempre en el fondo, con el murmullo de helicópteros volando encima, los más de mil alumnos del colegio pasamos el día entero: aislados durante casi siete horas, recluidos de aquel combate que parecía no terminar nunca justo enfrente del colegio (Halfon, 2012, pp. 51-52).

Como se observa, a pesar de la naturalidad con la que se habla sobre que eran días de disparos, el enfrentamiento había pasado los límites de lo que se podía tolerar. Aunque si se conoce el antecedente histórico es fácil para el lector relacionar lo leído con lo que pasó en Guatemala en 1981, aun así, el autor se preocupa por complementar el episodio ficcional, el área oscura de McHale, ${ }^{10}$ mediante la presencia del discurso periodístico que se combina con los comentarios del niño:

Eran dos páginas enteras de fotos grises y opacas y de varios tamaños que narraban el combate del día anterior. Decía el titular, hasta arriba, en grandes letras negras "Cuartel guerrillero destruido en Vista Hermosa”. En una foto salía el rostro en perfil de un bombero, mientras escarbaba entre los residuos de concreto y hierro torcido: "La casa destruida fue calificada por las autoridades como cuartel general subversivo de los guerrilleros, en el combate más nutrido y de más duración registrado hasta ahora en la capital de la república". En otra foto había varias camillas con lo que parecían cadáveres: "Tras la artillería de una tanqueta, murieron aplastados catorce guerrilleros, once hombres y tres mujeres". $\mathrm{Al}$ centro de otra foto, entre ripio y escombros, había un bulto largo tapado con una manta: "En lo que quedaba de la sala se halló el cuerpo sin vida de uno de los guerrilleros, una guitarra chamuscada que aún conservaba sus cuerdas y la pantalla de un televisor en una esquina que se confundía con los restos de un esmeril". Pegado a ésta había otra foto, como de pasaporte o cédula, de un hombre muy moreno y de facciones indígenas: "Según informaron las autoridades, este guerrillero fue identificado como Roberto Batz Chocoj, albañil de Patzún, Chimaltenango". Hasta debajo de la página había una foto de un grupo de militares, todos serios, todos con ametralladoras o escopetas: "Al entrar los elementos del orden público a la casa, encontraron gran cantidad de armas diversas, minas Claymore, granadas rusas de fragmentación, fusiles M-16, subametralladoras y material explosivo dedicado a la fabricación de bombas caseras" (Halfon, 2012, pp. 58-59).

Como quizá puede apreciarse con el contrapunteo entre los comentarios del narrador y la introducción del discurso periodístico, al parecer citados directamente de algún diario de la época, se busca integrar el discurso ficcional y el histórico; sin embargo, no es hasta que el niño comienza a asimilar lo que estaba pasando - pues, hasta antes de ver el periódico, el niño parecía no dar importancia a los hechos ocurridos y solo trataba de divertirse- que se completa la integración entre ambos aspectos del cuento, y ello lo logra el autor a través de la pesadilla que el narrador tiene, donde su madre es raptada por un guerrillero:

Soñé que llegaba a nuestra casa el guerrillero de la guitarra chamuscada y el televisor. Saludaba al policía de seguridad en el vestíbulo, quien solo seguía tomando sorbitos de café de su termo. El guerrillero

\footnotetext{
${ }^{10}$ De acuerdo con McHale, las áreas oscuras son "aquellos aspectos acerca de los cuales los registros oficiales no tienen nada que informar" (2004, p. 87). La traducción es mía.
} 
subía las gradas y entraba en el cuarto de mis papás y salía cargando a mi mamá. Tenía a mi mamá cargada sobre un hombro de la misma forma en que se cargaría un costal de papas. Decía que quería llevársela con él a las montañas de Patzún, en Chimaltenango. Mi mamá estaba tranquila, parecía no protestar, parecía no importarle. Mi papá no estaba. De pronto el guerrillero se asomaba de espaldas a la puerta de mi cuarto, para que mi mamá se despidiera y ella, mucho más pequeñita sobre el hombro del colosal guerrillero, solo me decía adiós con la mano. Yo le gritaba que por favor no se fuera con el guerrillero de la guitarra y el televisor, que por favor no me abandonara, y mientras yo le gritaba mi mamá solo seguía diciéndome adiós con la mano (Halfon, 2012, pp. 67-68).

El niño despierta sudando y gritando y tiene una última conversación con el padre que llega a tranquilizarlo. Ahí, hablan sobre su salida al día siguiente a Miami y sobre los guerrilleros indígenas. Sin embargo, en conexión con los temores presentes en la pesadilla —combinación arbitraria de la realidad familiar del niño y de lo que había visto en el periódico - la plática se contrapuntea con lo que parece estar sucediendo en el exterior de la casa: el chirrido de los frenos de un auto que llega y se estaciona, que apaga el motor, dos puertas que se cierran y dos voces que hablan en sordina. De ahí que el final, después de que el padre del niño le dice que seguiría hablando de lo que era un guerrillero al otro día, pueda tener un doble significado: "Pronto llegó mañana y mañana nunca lo hablamos" (Halfon, 2012, p. 70). Me refiero a que el sueño podría estar advirtiendo sobre el posible secuestro de algún ser querido del niño o simplemente sobre la paranoia suscitada por el espaciotiempo de violencia en el que viven. En cualquiera de los dos casos, la realidad se vuelve intolerable y la migración pasa a ser la única salida. Si se atiende al carácter autobiográfico de la narrativa de Halfon, entonces, simplemente el niño de la historia nunca volvió a hablar con su padre del asunto, porque de los hechos traumáticos o políticamente delicados siempre se evita hablar. Pero como se sabe, una cosa es la biografía y otra el cuento. Vale la pena, sin embargo, mencionar que esa diáspora a la que como judío el niño del cuento parece estar condenado, la padeció en el mismo año Halfon, de ahí mucha de la importancia de lo autobiográfico:

Cuando yo tenía diez años [dice Halfon], mi familia tuvo que huir de Guatemala, aunque a mi padre no le gusta que yo diga 'huir' porque él lo ve más como una salida necesaria por la situación que había en Guatemala, con guerra interna y un dictador en el poder. Desde entonces, yo no he parado de moverme. El otro día se lo comentaba a mi pareja: yo no he pasado más de cinco o seis años en una misma casa desde que tenía diez años. Llevo toda mi vida con cajas, mudanzas y maletas. Es mi realidad. Incluso ahora que tengo un hijo. Yo estoy trabajando en Nebraska y todos mis libros los tengo en cajas, ni siquiera los he sacado porque sé que en unos años me volveré a mudar (Mendoza, 2018).

De alguna manera, ese desarraigo al que remite Halfon está presente en la voz del niño narrador y proviene, al menos en lo que se refiere al cuento, del contacto con la violencia, ya sea el Holocausto, la guerrilla o la dictadura de Guatemala. Vale comentar que, a pesar del comentario político que implica hablar de un dictador - se refiere al político Fernando Romeo Lucas García, quien fue presidente de Guatemala entre 1978 y 1982 cuando lo derrocó un golpe de Estado-, como lo hace en la entrevista, en el texto literario es muy cuidadoso y, quizá por eso mismo, al igual que Carrillo, según se mencionó arriba, usa a un niño como narrador, pues es a través de una perspectiva en formación como de manera 
verosímil se puede hablar de hechos terribles sin emitir juicios explícitos al respecto. Con ello se cuida el debido equilibrio entre los niveles ético y estético.

En relación con el carácter de literatura comprometida que señalé anteriormente, vale la pena comentar "El iluminado", de Leonor Paz y Paz. ${ }^{11}$ Este cuento corto trata de Lorenzo, sacerdote católico que siente culpa de las comodidades con las que vive cuando piensa en la gente pobre:

Lorenzo separaba los ojos del devocionario y pensaba en los campesinos que a esa hora iniciaban sus arduas faenas, labrando con el sudor de su frente una tierra ajena, que daría con creces salud, estudios, comodidades y hasta belleza a sus dueños, mientras en los ranchos, anémicos y palúdicos, con lombrices y desnutridos, crecían sus hijos (Paz y Paz, 2013, p. 97).

Esta forma de pensar que lo lleva a comparar su situación con la de los menos favorecidos es la que lo hace abandonar las comodidades de la ciudad para irse al campo, luego abandonar la tranquilidad de su parroquia para ayudar a los campesinos y, finalmente, dejar los hábitos para formar un movimiento revolucionario.

El texto, narrado en tercera persona y desde una perspectiva empática con el activismo a favor de los pobres - lo que puede significar que la voz autoral simpatiza con grupos de guerrilla-, es un texto ágil, pero, al contrario del texto de Halfon, se le da más peso a lo ideológico que a lo estético. Esta particularidad hace que el texto caiga por momentos en el panfleto. A pesar de ello, no es un mal cuento y es interesante porque, de alguna manera, enumera los distintos niveles de conciencia por los que un activista político podría haber transitado para llegar a la guerrilla; por ejemplo, el personaje inicia con la toma de conciencia de clase - él y los otros seminaristas rezan mientras la gente afuera tiene hambre-, esta conciencia le da los elementos para llevar a cabo una crítica a la institución a la pertenece, la Iglesia, pues las finas prendas con las que oficia y los carísimos cirios contrastan con la pobreza de los fieles - Lorenzo, incluso, recuerda que las tías que habían estado tan felices cuando se ordenó sacerdote habían sufrido para comprarle durante su infancia zapatos o una camisa y para darle de comer-; posteriormente, cuando decide alejarse de las comodidades de la urbe para irse al campo, ve que sus manos suaves no merecen las tres comidas que tiene sin problemas en su mesa, pues los campesinos que trabajan al sol no disfrutan lo mismo que él; finalmente, no puede evitar que una mujer con problemas de nutrición muera durante su trabajo de parto por lo que, incluso, critica al mismo Dios que representa (Paz y Paz, 2013, p. 100). Es, entonces, cuando cuelga los hábitos y decide luchar.

Vale comentar que, aunque Lorenzo es un personaje idealizado que tiende a la perfección, lo que motiva su movilización política son razones propiamente ideológicas en cuanto a lo material se refiere y otras más personales propiciadas por los efectos de la religión católica, como la culpa. Parece que, a diferencia de la mayoría, Lorenzo no puede ser feliz cuando él está en la parte favorecida de una sociedad que no se caracteriza propiamente por el equilibrio y la justicia. El final no puede ser más revelador, pues sus fieles, cuando lo ven llegar en ropa de civil, sin la sotana acostumbrada, le preguntan por cómo lo

\footnotetext{
${ }^{11}$ Según Francisco Albizúrez Palma, Leonor Paz y Paz nación en Zacapa en 1932, murió en la Ciudad de Guatemala en 2000 y es poeta - Hojas de abril (1957), Fantasía y realidad (1968) y Cartas a los maestros (1960) - y narradora - Lo que se calla (1963), Tanta Esperanza (1963), La mujer de pelo largo (1967) y Como si fueran cuentos (1978) - (Albizúrez, 2013a, p. 95).
} 
llamarán ahora, a lo que Lorenzo responde: "Llámenme compañero, da lo mismo" (Paz y Paz, 2013, p. 101). Término, el de "compañero" que, como el de "camarada", pretende dar cuenta en el trato diario de la igualdad de todas las personas. De esta manera, el texto funciona como una especie de exemplum -en el sentido de texto narrativo que sirve como argumento para demostrar una idea- que da cuenta de que el interés por los otros y por la justicia parte de una igualdad real y no simulada.

\section{A manera de conclusión}

Como quizá pudo observarse, los seis textos aquí revisados tienen algún elemento de carácter social, y si bien hay algunos que contienen elementos metaficcionales que permiten la reflexión sobre el proceso de escritura o poseen los niveles estético y estilístico muy trabajados, hay siempre una preocupación por referir una serie de argumentos desde el tiempo de la enunciación sobre una realidad presente o pasada algo complicada. Así, por ejemplo, en "Nuestra señora de los locos" o en "Imitando se entiende la gente", se oculta mediante la comparación de algunos personajes con animales un trasfondo ideológico del que no puede hablarse directamente o se da cuenta de que la propaganda puede hacerse, quizá como truco retórico, incluso si se tienen los mismos prejuicios que la mayoría respecto de lo pregonado. En "El vuelo de la Jacinta" y en "Morgan" se usa la acriticidad de los narradores como una manera de hacer artísticamente una crítica a los abusos, sexuales o no, de los que son víctimas los hijos con o sin el conocimiento de alguno de los padres; asimismo, esa acriticidad, que se identifica en "Morgan" con desenfado, sirve como una manera de evidenciar la humanidad de un ser que se automargina en el mundo de las drogas.

En "Mañana nunca lo hablamos" se logra la interacción de la historia y la ficción a través de los datos biográficos del autor empírico y del discurso onírico con el fin de señalar las contradicciones de un grupo pudiente condenado a migrar en parte por el destino y en parte por las condiciones propias de América Latina; asimismo, en "El iluminado" se ficcionalizan las distintas etapas de conversión de un sacerdote con conciencia del otro en un guerrillero en busca de la revolución. Como se trató de hacer notar, el discurso literario, aún el de calidad, refiere, y no lo puede evitar, una realidad. Ello no tiene nada de malo y sí mucho de qué dar cuenta. Solo espera a ser descodificado. En este sentido, vale comentar que las interpretaciones aquí vertidas no tienen el fin de ser definitivas o totalitarias, pero sí de enfatizar la falta de estudios desde Norteamérica de la obra de escritores centroamericanos, pues, de alguna manera, la cercanía de México a Estados Unidos ha llevado a descuidar la frontera sur en muchos de sus flancos.

\section{Referencias}

Alvarado, C. L. (2013). Arévalo Martíne y la Generación del Cometa. Revista Luna Park. Literatura y Arte, (12). https://revistalunapark.wordpress.com/2013/04/07/literatura-guatemalteca-arevalo-martinez-y-lageneracion-del-cometa/

Albizúrez Palma, F. (2013a). Leonor Paz y Paz. En Fuera del círculo. Antología guatemalteca II (p. 95). Alfaguara.

Albizúrez Palma, F. (2013b). Prólogo. En Fuera del círculo. Antología guatemalteca II (pp. 9-12). Alfaguara.

Albizúrez Palma, F. (2013c). Raúl Carrillo. En Fuera del círculo. Antología guatemalteca II (p. 35). Alfaguara.

Arévalo Martínez, R. (2011). Nuestra señora de los locos. En Narrativa guatemalteca. Antología (pp. 37-57). Alfaguara.

Carrillo, R. (2013). El vuelo de la Jacinta. En Fuera del círculo. Antología guatemalteca II (pp. 37-43). Alfaguara. 
Ceballos-Fernández, M. (2014). Identidad homosexual y contexto familiar heteroparental: implicaciones educativas para la subversión social. Revista Latinoamericana de Ciencias Sociales, Niñez y Juventud, (12), 643-658.

Cordero, M. (2009, 7 de febrero). El vuelo de Raúl Carrillo. La Hora. https://lahora.gt/hemeroteca-lh/el-vuelode-raul-carrillo/

Chávez Alfaro, I. (2005). Crónicas suburbanas, de Francisco Alejandro Méndez: desde el espacio de la posmodernidad. En América Central en el ojo de sus propios críticos. Una visión desde adentro hacia una literatura desde adentro (pp. 13-29). Universidad Rafael Landívar; Abrapalabra. http://biblio3.url.edu.gt/Publi/Libros/ ACOjoCriticos.pdf

EcuRed. (2019). Manuel Estrada Cabrera. https://www.ecured.cu/Manuel Estrada_Cabrera

Equipo Nizkor. (2011). Del silencio a la memoria. Revelaciones del Archivo Histórico de la Policía Nacional. Volumen 1 [Cuarta parte]. http://www.derechos.org/nizkor/guatemala/doc/pn4.html

Gallardo Linares, F. J. (2013). Identidad furry en España y sus prácticas de género. Un análisis crítico del discurso. En Aposta. Revista de Ciencias Sociales, (57), 1-26. http://www.apostadigital.com/revistav3/ hemeroteca/jglinares.pdf

Halfon, E. (2012). Mañana nunca lo hablamos. En Ni hermosa ni maldita. Narrativa guatemalteca actual (pp. 51-70). Alfaguara.

McHale, B. (2004). Postmodernist Fiction. Routledge.

Méndez, F. A. (2012). Morgan. En Ni hermosa ni maldita. Narrativa guatemalteca actual (pp. 93-101). Alfaguara.

Mendoza, A. (2018, 27 de junio). Entrevistas. Eduardo Halfon: "La ansiedad de vivir es algo muy judío". Zenda. Autores, libros y compañía. https://www.zendalibros.com/eduardo-halfon-la-ansiedad-vivir-algo-judio/

Moody, R. A. (1967). The Life and Prose Style of Rafael Arévalo Martínez [tesis de doctorado, University of California].

Muñoz Reoyo, A. (1997). "El hombre que parecía un caballo": La prefiguración de las técnicas de la vanguardia. Anales de Literatura Hispanoamericana, 26(2), 325-332.

Noguerol Jiménez, F. (1998). Rafael Arévalo Martínez, en los difusos límites entre el modernismo y la vanguardia. En T. Barrera (ed.), Modernismo y modernidad en el ámbito hispánico. Actas del II Congreso de la AEELH (pp. 202-214). Universidad Internacional de Andalucía.

Palencia-Frener, S. G. (2014). Rebelión social y contrainsurgencia en Guatemala, 1981-1983. Conformación estatal y potencialidad revolucionaria. LiminaR. Estudios Sociales y Humanísticos, 7(1), 161-176.

Paz y Paz, L. (2013). El iluminado. En Fuera del círculo. Antología guatemalteca II (pp. 97-101). Alfaguara.

Romero, R. (2012). Imitando se entiende la gente. En Ni hermosa ni maldita. Narrativa guatemalteca actual (pp. 75 80). Alfaguara.

Salgado, M. A. (1977). La narrativa de Rafael Arévalo Martínez: el autor frente a su obra. En Actas del Quinto Congreso de la Asociación Internacional de Hispanistas: celebrado en Bordeaux del 2 al 8 de septiembre de 1974 (pp. 777 -

782). Instituto de Estudios Ibéricos e Iberoamericanos-Université de Bordeaux III.

Villalobos, E. (2011). Narrativa guatemalteca. Antología. Alfaguara.

Villalobos, E. y Méndez Salinas, L. (2012). Ni hermosa ni maldita. Narrativa guatemalteca actual. Alfaguara. 